\title{
Effect of lead acetate injection into pregnant mice on the testis function of their male offspring at puberty
}

$$
\begin{aligned}
& \text { ثير حقن اناث الفئران الحوامل بمادة خلات الرصاص على وظيفة } \\
& \text { الخصى لمواليدها الأكور عند البلوغ خلوغ الرصاه }
\end{aligned}
$$

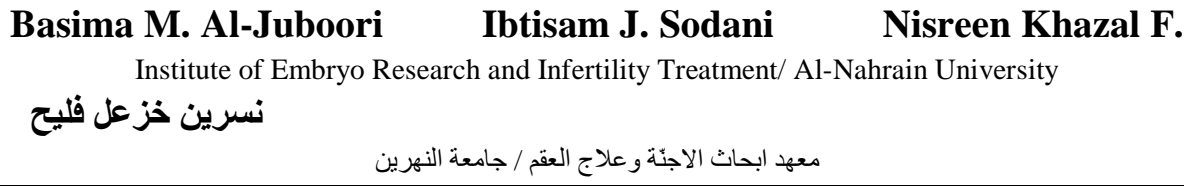

\section{Abstract}

(U) he study aimed to follow up the effects of injection lead acetate into pregnant females on the testicular development and semen quality of their male births at puberty time. Forty mature female Swiss Webster mice (8-10) weeks old were divided into two equal groups (experimental and control). After mating with fertile males, the pregnant females injected intraperitoneally with $0.1 \mathrm{mg} / \mathrm{kg}$ of body weight of lead acetate from the first day of gestation and continued throughout the gestation period 20 days. While the control groups were injected by the same dose and rout of injection with normal saline. At parturition, numbers of the neonate were recorded. After six weeks the male births only isolated and weighted then mated with normal fertile females to evaluate their fertility through assessing their birth rate, then sacrificed to get their testes; each testis was weighted and the left one was fixed, then histological sections with a thickness of 5 microns were prepared. The epididymis was minced with warm normal saline to get a spermatozoal suspension to evaluate the sperm concentration, sperm motility, and abnormal sperm morphology and sperm viability. Results showed a highly significant decrease in the body and testicular weights of experimental male animals. A highly significant reduction in their birth rate after mating with normal partners was recorded together with a significant inverse changes in all semen parameters.

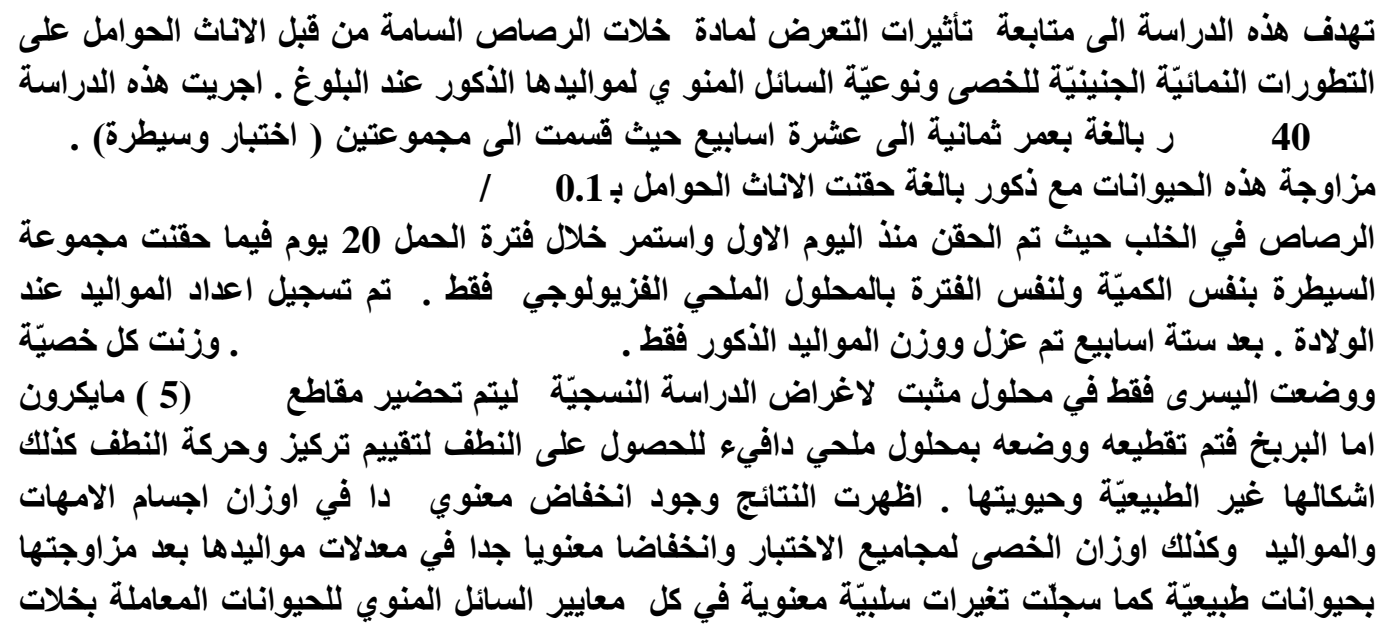




\section{Introduction}

Lead has become widely distributed and mobilized in the environment. Human exposure and uptake of this element has consequently increased [1]. Lead stays in the body for much longer than most metals, with a half-life of 11 years in the bone [2]. It is used widely in industry for its waterproofing and electrical and radiation-shielding properties [3]. At higher level of human exposure, there is damage to almost all organs and systems, most importantly the central nervous system (CNS), kidneys, blood, skeletal, gastro-intestinal and respiratory systems [4]. Lead poisoning impairs both male and female reproductive function in adult and developmental stages lead to death in the embryo, fetus or child [5]. Reported effects on men include; reduction in libido, sperm quality (motility, numbers, and morphology) chromosomal damage, infertility, abnormal prostatic function and changes in serum testosterone level [6]. Increased lead concentration may contribute to production of unexplained male infertility [7]. In order to follow up the effect of lead on the function of testes and semen quality of young male offspring born from mothers exposed to lead acetate during gestation, this study was conducted.

\section{Materials and methods}

Forty mature female Swiss Webster mice (8-10)weeks old were divided into two equal groups: experimental (G) and control (C). Vaginal smear were performed to all adult female mice to detect heat stage for mating. Females in the metestrus phase were left with mature healthy males (1male/ 1female), the occurrence of vaginal plug considered as the first day of pregnancy [8]. The pregnant female was removed into separate cage. Intraperitoneally injection of lead acetate $(0.1 \mathrm{mg} / \mathrm{kg}$ body weight/day) [9], was started at the first day of gestation and continued through gestation period 20 day for the experimental group, while the parallel control group was injected normal saline by the same rout and dose as that used in the experimental group. At parturition, numbers of the offspring for all experimental and control mothers were recorded. After six weeks (around the puberty age) the newborn animals (males only) were weighted, mated with fertile females (to detect their ability for fertilization and then recording their birth rate), and then sacrificed to get their testes. Each testis was weighted, then the left one was fixed with $10 \%$ normal saline, and histological sections with a thickness of 5 microns were prepared using the routine histological technique [10]. Thickness and diameter of seminiferous tubules in each testis were recorded. The epididymis was put in a small Petri dish containing worm normal saline, organ were minced into tiny pieces with micro surgical scissors until getting a homogenized solution, which contain the spermatozoal suspension then incubated at $37 \mathrm{C}^{\circ}$ befor subjected to sperm function test, including microscopic examination to record the concentration of spermatozoa (sperm / ml), sperm motility (Grade A, B, C, D), abnormal sperm morphology and sperm viability by using eosin stain. Statistical analysis were performed using version 7.5 SPSS (Statistical analysis Package for Social Scientists) to determine the mean and standard error of mean. P- Value $<0.05$ was considered significant in this study [12]. 


\section{Results}

\section{Effect of lead on fertility of young males}

The young males borne from mothers treated with lead acetate during gestation period showed a reduction in their fertility when mated with fertile normal females, revealed by a highly significant decrease $(\mathrm{P}<0.01)$ in their litter size as compared to the parallel control group Table (1).

\section{Effect of lead on body and testes weights of young male mice}

The result showed that there was a highly significant decrease $(\mathrm{P}<0.01)$ in the mean of the body weights and a significant decrease $(\mathrm{P}<0.05)$ in testes weight of experimental groups as compared to the control group Table (1).

\section{Effect of lead on semen quality (sperm function test) of young males:}

Results showed significant decrease $(\mathrm{P}<0.05)$ in the percentage of epididymal viable sperms of experimental group with a highly significant reduction in sperm concentration $(\mathrm{P}<0.01)$ associated with a highly significant decrease in percentage of grade activity (A, B , C) and a highly significant increase in percentage of grade activity (D). Also a significant increase $(\mathrm{P}<0.05)$ in the number of sperms with abnormal morphology was recorded in the experimental animals in comparison with that of control group Table (2).

\section{Histological observations:}

The histological observations of the testes of male offspring showed a significant decline $(\mathrm{P}<0.05)$ in the thickness and diameter of semineferous tubules with a degenerative features of germ cells, disrupting of basal lamina, sloughing cells and absence of sperms from some of semineferous tubules was also recorded Figure $(1,2)$. Table (1): Effect of exposure to lead during the intrauterine life on the fertility and weights of body and testes of young males offspring.

\begin{tabular}{ccc}
\hline & Experimental group(G) & Control group(C) \\
Birth rate & $5.6 * *$ & 7.7 \\
& \pm 0.063 & \pm 0.04 \\
Body weight of & $16.3 * *$ & 19.3 \\
offspring at & \pm 0.038 & \pm 0.028 \\
puberty $(\mathrm{g})$ & & \\
Weight of testis $(\mathrm{g})$ & $0.13 *$ & 0.14 \\
& \pm 0.0007 & \pm 0.0008 \\
Thickness of & $1.25 *$ & 1.77 \\
semineferous & \pm 0.0003 & \pm 0.0005 \\
tubules $(\mu \mathrm{m})$ & & \\
Diameter of & $12.5 *$ & 13.6 \\
semineferous & \pm 0.03 & \pm 0.002 \\
tubules $(\mu \mathrm{m})$ & & \\
\hline
\end{tabular}

Values are mean \pm standard error (SEM).

**: Highly significant decrease $(P<0.01)$.

*: significant decrease $(\mathbf{P}<0.05)$. 
Table (2): Effect of exposure to lead during the intrauterine life on the semen quality of young males offspring.

$\begin{array}{ccc}\text { Seminal fluid analysis } & \begin{array}{c}\text { Experimental } \\ \text { group }(\mathbf{G})\end{array} & \text { Control group(C) } \\ \text { Sperm concentration } & 45 * \star & 51.5 \\ \text { (million /ml) } & \pm 0.07 & \pm 0.08 \\ \text { Sperm motility } & 10.6 \star \star & 21 \\ \text { Grade A } & \pm 0.1 & \pm 0.07 \\ \text { Grade B } & 37.5 * \star & 48 \\ & \pm 0.03 & \pm 0.1 \\ \text { Grade C } & 13 \star \star & 19.2 \\ & \pm 0.07 & \pm 0.2 \\ \text { Grade D } \quad 39 \star * & 11.5 \\ & \pm 0.07 & \pm 0.1 \\ \text { Abnormal } & 78.5 * & 72.5 \\ \text { Morphology } & \pm 0.21 & \pm 0.17 \\ \text { Viability } & 18.5 * & 20 \\ & \pm 0.06 & \pm 0.05\end{array}$

Values are mean \pm standard error (SEM).

**: Highly significant decrease $(\mathbf{P}<0.01)$.

*: significant decrease $(\mathrm{P}<0.05)$.

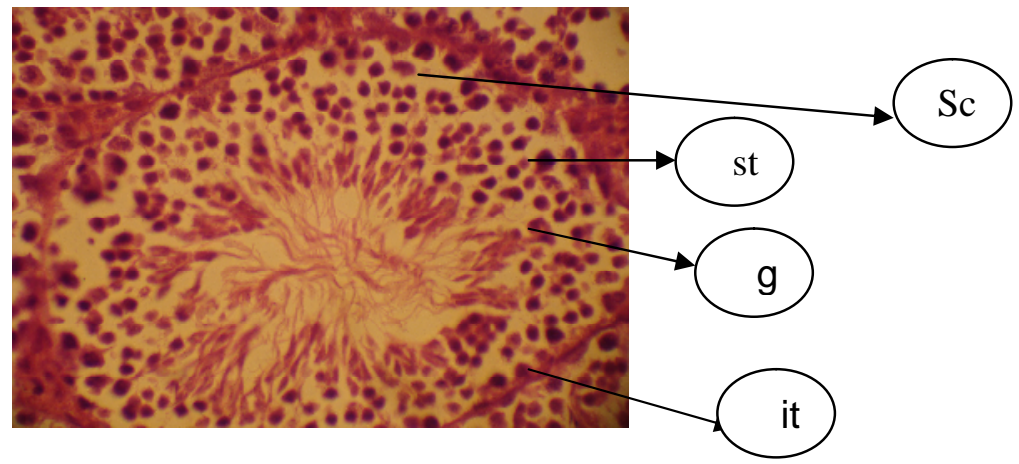

Fig (1): Testis section of male mouse offspring (control group). Note the well organized seminiferous tubules (st) filled with germ cells (g) and Sertoli cells (Sc), with extensive interstitial tissue (it) (H\&E, 40X).

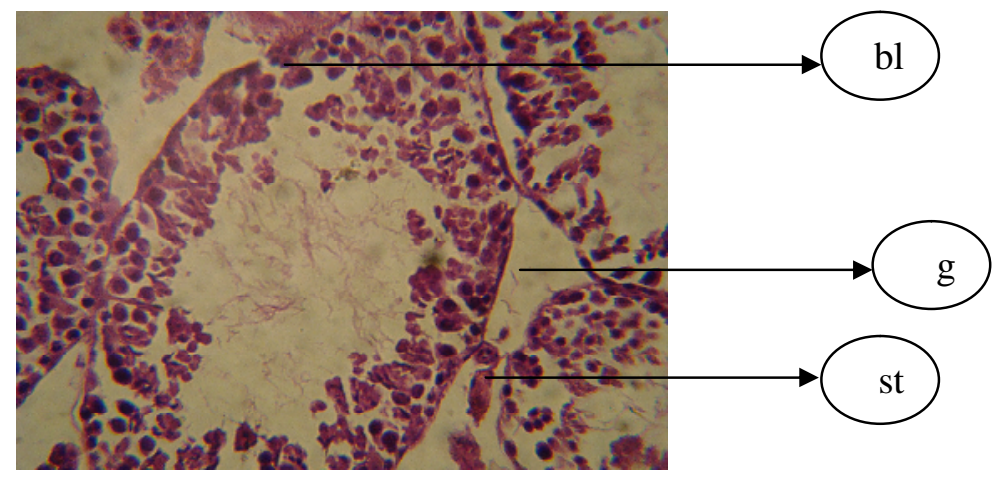

Fig (2): Testis section of male mouse offspring belong to mother treated with $(0.1 \mathrm{mg} / \mathrm{kg} \mathrm{b.w.)} \mathrm{of}$ lead acetate. Note a significant decline in the thickness and diameter of seminiferous tubules (st) with degenerative features germ cells (g), disrupting of basal lamina (bl), sloughing cells and absence of sperms from some of seminiferous tubules (st) (H\&E, 4nX) 


\section{Discussion}

Several studies confirm that lead is able to pass through the placenta of pregnant female mice, presumably by passive diffusion and accumulate in embryo tissues interfering with embryo implantation [13]. This passage of lead with what is known about its persistence in body for longer time than other metals [14], may explain all the adverse results recorded in this study including the reduction their ability to fertilize normal females which expressed by the significant decrease in their birth rate compared to that of control group. This reduction in fertility goes with other findings including impaired semen parameters and reduction in body and testes weight. The decrease in body weights of experimental males may be related to the decrease in feeding habit, which may lead to growth retardation indicating that lead has an inhibitory action on metabolism [15], which agreed with finding recorded that human with elevated level of lead have depressed secretion of several hormones including metabolic hormones [16]. On the other hand the significant reduction in sperm concentration recorded, may be due to reduction in sperm production in testes since lead could disturb mitosis in vivo and alter Sertoli cells proliferation at perinatal period which could produce a significant decrease of sperm count in the testes of adult offspring [17]. The sperm motility and grade of activity are one of the most important criteria of semen quality and a determinant in the success of fertilization [11], the reduction of motility may be due to the direct effect of lead on the sperm cells [17], or it may affect the epididymis since Prased and Raja [18] showed that sperm motility is dependent on the phospholipids that found in caput epididymis as a source of energy. In the present study there was a significant increase in abnormal sperm morphology within epididymis, similar results were also reported by [19] in mice semen collected after an acute exposure to lead acetate. [20] reported that the lead was accumulate in all the male reproductive organs with especially high concentration of lead in the epididymis where it have caused alteration in the functions of epididymis which lead to the abnormal morphology of sperm. Results of present study showed a significant decrease in the percentages of viability in experimental group as compared with control group. [21] showed that the presence of lead in the seminal plasma exerts toxic effects on sperm parameters such as morphology, motility and viability. Therefore, adverse changes in epididymal and testicular sperm structure lead to nonviable sperm production. Degenerative features in the testes of male offspring of experimental group revealed by a significant decline in the thickness of seminiferous tubules and reduction in the diameter of testes may be due to accumulation of lead in the gonads and testicular tissues which affects the physiology of reproduction [22], necrosis of testicular cords, degenerative primordial germ cells, disrupting of basal lamina, sloughing cells and absence of sperm from some seminiferous tubules. These results agree with those obtained by [23] in which the weight of testes was dropped significantly in 22 day old male rats exposed to lead prenataly. It was proved [24] that lead exposure during a period of pregnancy when structures related to the Hypothalamus Pituitary Gonadal (HPG) axis are undergoing rapid proliferation, the 
exposed animals at significant risk for reduced reproductive capacity in adulthood, and elicit toxic pathological changes in the testes leading to atrophy of the organ.

\section{Reference}

1. Markowitz, G. and D. Rosner (2000). (Cater to the children), the role of the lead industry in a public health tragedy, 1900-1950. Am. J. public health. 90; 36-46.

2. Cheng, Y.; Schwartz, J.; Sparrow, A.; Aro, S.T.; Weiss and Hu, H. (2001). Bone lead and blood lead levels in relation to baseline blood pressure and the prospective development of hypertension; the Normative Aging Study. Am. J. Epidemiol. 153(2); 164-71.

3. Lyn- Patrick, N.D. (2006). Lead toxicity, a review of the literature, Part 1. Exposure, evaluation and treatment. 2530. Colorado Avenue, suite 2c, Durango, co 81301.11: 1-11.

4. Christopher, P. and Holstege, M.D. (2007). Medicine - Lead Encephalopaty; Article, FACEP, and FACMT.

5. Sowers and Maryfran (2002). Blood Lead Concentrations and Pregnancy Outcomes Archives of Environmental Health. Vol. 57, issue 4, p489-496.

6. Benoff, S.; Jacob, A.; Hurley, IR. (2000). Male infertility and environmental exposure to lead and cadmium. Hum. Reprod. Update. 6; 107-21.

7. Benoff, S. (2003). Seminal lead concentrations negatively affect outcome of artificial inseminations Fertil. Sterl. 80: 3517-525.

8. Roberts, R.V. (1968). The mouse its reproduction and development. P 54.

9. Koller LD, Kerkvliet NI, Exon JH (1985). Neoplasia induced in male rats fed, lead acetate, ethyl urea, and sodium nitrate. Toxicol Pathol. 13(1):50-7.

10. Bancroft, J.D. and Steven, A. (1982). Theory and practice of histological techniques. Churchill, Livingston, London, 2nd. ed. Pp110-111.

11. World health organization (WHO) (1999). Laboratory manual for the examination of human semen and sperm, Cambridge university press.

12. Sorlie, DE. (1995). Medical Biostatistics and Epidemiology: examination and board review. First edition. Appelton and Lange, Norwalk, Connecticut. Pp 47-88.

13. Wide, M. and Nilsson, O. (1977). Differential susceptibility of the embryo to inorganic lead during perimplantation in the mouse Teratology. 16: 273-276.

14. Rania Habal, M.D. (2006). Toxicity, Lead. Department of Emergency Medicine, New York Medical College.

15. John, T. (2002). Introduction to Toxicology. Third ed. Boca Raton, London, New York, Washington. D.C. Pp 128-89.

16. Huseman. C.A., Varma, M.M., and Angle C.R., (1992). Neuroindocrine effects of toxic and low blood lead levels in children. Pediatrics, 90:186-189.

17. Telisman, S.; Cvitkovic, P.; Jurasovic, J.; Pizent, A.; Gavella, M. and Rocic, B. (2000). Semen quality and reproductive endocrine function in relation to biomarkers of lead, cadmium, zinc and copper in man. Environmental Health Perspectives. 108(1): 45-53.

18. Prased, M.R. and Raja Lakshmi, (1976). Comparative physiology of the mammalian epididymis. Gen. Comp. Endocrinol. 28:530-537. 
19. Wyrobeck, A.J. and Bruce, W.R. (1978). The induction of sperm-shaped abnormalities in mice and humans. Chem. Mutat. 5: 257-285.

20. Johnson, L. and Wide, M. (1986). Long term exposure of the male mouse to lead: effect on fertility. Environ. Res. 41: 481-487.

21. Dawson, E.B.; Ritter, S.S.; Harris, W.A.; Evans, D.R. and Powell, L.C. (1998). Comparison of sperm viability with seminal plasma metal levels. Bio. Trace Elem. Res. 64: 97-107.

22. Acharya, U.R. and Mishra, P. (1995). Lead induced histopathological changes in the testes of Swiss mice. Adv. Biosci. 14: 37-44.

23. Thoreux-Manlay, A.; Velezdelacalle, J.F.; Olivier, M.F.; Soufir, J.C.; Masse, R. and Pinon-Lataillade, G. (1995). Impairment of testicular endocrine function after lead intoxication in the adult rat. Toxico. 100; 101-109.

24. McGivern, R.F; Sokol, R.Z. and Berman, N.G. (1991). Prenatal lead exposure in the rat during the third week of gestation; Long-term behavioral, physiological and anatomical effects associated with reproduction. Toxicol. Appl. Pharmacol. 110: 206-215. 